\title{
Sterol Metabolism
}

\section{THE INTERCONVERSION OF CHOLESTEROL, 7-DEHYDROCHOLESTEROL AND LATHOSTEROL IN THE RAT*}

\author{
By E. I. MERCER AND J. GLOVER \\ Biochemistry Department, University of Liverpool
}

(Received 27 February 1961)

The three closely related sterols, cholesterol, 7-dehydrocholesterol and lathosterol, occur in animal tissues in different proportions. From their structures they would appear to be interconvertible by simple dehydrogenation or reduction steps as shown in Fig. 1, but unequivocal evidence for such a mechanism has not yet been obtained.

It has generally been assumed that 7-dehydrocholesterol (provitamin D) is formed in vivo by dehydrogenation of cholesterol, and observations on the feeding of cholesterol to guinea pigs supported this concept (Glover, Glover \& Morton, 1952). The work was done, however, before the discovery of lathosterol, which is difficult to separate from its isomer cholesterol. It has been shown that lathosterol can be converted into cholesterol in vivo (Cook, Kliman \& Fieser, 1954) and in vitro (Frantz, Davidson, Dulit \& Mobberley, 1959 ; Mercer \& Glover, 1959), but the intermediates have not yet been established. The formation of cholesterol from zymosterol (Johnston \& Bloch, 1957) and lathosterol (Frantz et al. 1959) requires aerobic conditions, which has tentatively been interpreted as perhaps involving hydroxylation followed by a dehydration step. This process would not easily be reversible. The rapid and extensive reduction of 7-dehydrocholesterol to lathosterol that takes place in the guinea pig and in the rat (Glover \& Green, 1957; Glover \& Stainer, 1959)

* Part 5: Glover, Green \& Stainer (1959). implies that direct reduction of the $\mathrm{C}_{(5)}$ double bond occurs very readily in both species. It is perhaps simplest therefore for the present to assume that a reductase works reversibly. Evidence for the reduction of the $C_{(7)}$ bond of provitamin $D$ to give cholesterol was not clear-cut in the same balance studies. The equivocal result for the latter reduction possibly arises because $(a)$ it proceeds relatively slowly compared with the absorption of the product, and (b) the normal exchange and mixing of endogenous cholesterol and dietary sterols during absorption always result in sweeping some endogenous sterols into the lymph. Consequently a more critical experiment on the metabolism of $\left[4^{-14} \mathrm{C}\right]$ cholesterol in the rat has been carried out.

Other experiments with pure preparations of lathosterol, 7-dehydrocholesterol and cholesterol were also undertaken to determine if these three sterols were easily interconvertible in the rat. First, changes in the mucosal sterols of the small intestine were followed during the absorption of cholesterol and lathosterol in turn. Secondly, the interconversion of the various sterols was studied in vitro by using everted sacs of rat intestine.

\section{EXPERIMENTAL}

Materials. Cholesterol (British Drug Houses Ltd.) was purified by the dibromide technique of Schwenk \& Werthessen (1952). The product was crystallized twice from

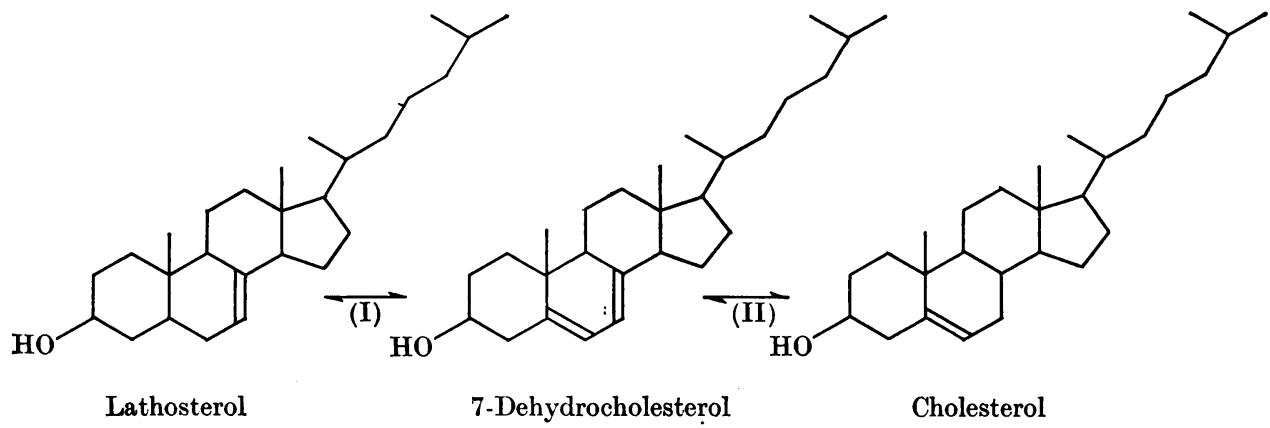

Fig. 1. Scheme showing the interrelationship of lathosterol, 7-dehydrocholesterol and cholesterol. The enzyme systems (I) and (II) are represented as reductases of $\mathrm{C}_{(5)}$ and $\mathrm{C}_{(7)}$ double bonds respectively of 7-dehydrocholesterol. 
methanol. 7-Dehydrocholesterol (cholesta-5:7-dienol) (Peboc Ltd., Liverpool) was freshly crystallized from methanol as required. Lathosterol (cholest-7-enol) was prepared from 7-dehydrocholesterol by the method of Schenck, Buchholz \& Wiese (1936). Last traces of 7-dehydrocholesterol were removed from the product by chromatography on $\mathrm{MgO}$ with $2 \%(\mathrm{v} / \mathrm{v})$ diethyl ether in light petroleum (b.p. $40-60^{\circ}$ ) as the eluent. The lathosterol was crystallized several times from methanol. The crystals melted at $123^{\circ}$ and had the correct i.r. spectrum, and the u.v. spectrum showed no residual 7-dehydrocholesterol. [4-14 C]Cholesterol (22 mc/m-mole) was obtained from The Radiochemical Centre, Amersham, and stored at $0^{\circ}$ in benzene solution. Before use it was diluted with pure cholesterol, and the resulting mixture purified from any radiation decomposition products by the dibromide procedure as above.

Animals. Male rats (wt. 150-250 g.) were selected and separated into uniform groups of four litter mates or animals of same weight and age. They were maintained on the cube diet no. 4 (British Extracting Co. Ltd., Port Sunlight). Each group of rats was placed on a diet of lipidfree food cubes (the above diet exhaustively extracted with ether) for 4 or 5 days before the start of the experiment. The rats were starved for $24 \mathrm{hr}$. before being dosed with sterol. In the lathosterol experiment $27 \mathrm{mg}$. was given to each rat but in the cholesterol experiments doses of $50 \mathrm{mg}$. were used. The cholesterol was suspended in the minimum of arachis oil $(0.5 \mathrm{ml} . / \mathrm{rat})$ and mixed with a small amount of extracted food cubes ( $3 \mathrm{~g}$./rat). The rats always ate the whole of the dose within $30 \mathrm{~min}$. of its being presented. They and the controls were killed $3 \mathrm{hr}$. later with $\mathrm{CHCl}_{3}$ and the small intestines were exeised for sterol analysis. The animals from which intestinal sacs were prepared were killed by a blow on the back of the neck.

In the experiments with $\left[4-{ }^{14} \mathrm{C}\right] \mathrm{cholesterol,} \mathrm{four} \mathrm{male}$ rats were dosed with $10 \mathrm{mg}$. each $(0 \cdot 43 \mu \mathrm{c} / \mathrm{mg}$.).

Preparation of everted intestinal sacs. These were prepared by the method of Wilson \& Wiseman (1954). The length of small intestine (measured from the pyloric sphincter) taken from each animal in the control and test groups was the same. In Expts. 9-14 the sacs were incubated in the medium used by Smith, Hauk \& Treadwell (1958), the sterols being held in suspension by means of bovine serum albumin $(5 \mathrm{mg} . / \mathrm{ml}$.). The sacs were filled and slightly distended with the medium minus the albumin, sterol and glucose. The sacs were incubated for $3 \mathrm{hr}$. at $37^{\circ}$. A gas mixture of $\mathrm{O}_{2}+\mathrm{CO}_{2}(95: 5, \mathrm{v} / \mathrm{v})$ was passed over the incubation mixture, which was shaken throughout at a rate of 60 excursions/min.

Isolation of intestinal mucosal lipids. The small intestine was washed with $0.9 \% \mathrm{NaCl}$, cut open and placed on a glass surface cooled with salt-ice mixture underneath, and the mucosa scraped off with a blunt scalpel. The everted intestinal sacs from experiments in vitro were treated similarly at the end of the incubation period. In a few experiments the lipids were extracted directly from the mucosa by the procedure described by Glover, Goodwin \& Morton (1947); however, in the majority of cases the mucosa was saponified and the non-saponifiable matter extracted as follows. Mucosa ( $x$ g.) was refluxed for $1 \mathrm{hr}$. with $x \mathrm{ml}$. of $0.25 \%$ pyrogallol in ethanol and $\frac{1}{2} x \mathrm{ml}$. of aq. $60 \% \mathrm{KOH}$. The mixture was then cooled, diluted with 3 vol. of distilled water and extracted five times with dry peroxide- free ether. The bulked extracts were washed free of alkali with water, dried over anhydrous $\mathrm{Na}_{2} \mathrm{SO}_{4}$ and evaporated under $\mathrm{N}_{2}$. This saponification process has no effect on the sterols and does not alter the relative proportions of 'slowacting' to 'fast-acting' sterols.

Extraction of sterols from non-saponifiable matter in experiments with ${ }^{14} \mathrm{C}$. The $3 \beta$-hydroxy sterols were separated from the non-saponifiable material by precipitation as their digitonides (Windaus, 1909) and regenerated by the method of Schoenheimer \& Dam (1933).

Chromatographic separation of 'slow-acting' cholesterol from 'fast-acting' sterols in experiments with $\left[4-{ }^{14} \mathrm{C}\right]$ cholesterol. The mixed sterols were esterified with azobenzene4-benzoyl chloride [4-(phenylazo)benzoyl chloride] and chromatographed on a column of silicic acid-Celite 503 $(2: 1, w / w)$, with light petroleum-benzene $(10: 1, v / v)$ for development of the chromatogram (Idler \& Baumann, 1952). When the two orange zones had completely separated the column was run dry and extruded. The zones were then cut out and extracted with benzene-ethanol (50:50, $\mathrm{v} / \mathrm{v}$ ). The upper zone consists of the azo esters of the 'fastreacting' sterols (mainly lathosterol and 7-dehydrocholesterol) and the lower zone is the cholesteryl azo ester. The free sterols were regenerated from their azo esters by the saponification method of Idler \& Baumann (1952).

Estimation of sterols. The 'slow-reacting' and 'fastreacting' sterols were assayed by the method of Moore \& Baumann (1952). The extinctions were read in the Unicam SP. 600 visual spectrophotometer at $620 \mathrm{~m} \mu$. 7-Dehydrocholesterol was determined spectrophotometrically by taking the u.v.-absorption spectra of either the lipid, or unsaponifiable matter or mixed sterol in ethanol and correcting for irrelevant absorption with the Morton \& Stubbs (1946) three-point correction procedure. The wavelengths selected were $276.5,281.5$ and $298 \mathrm{~m} \mu$, and the corresponding extinctions $E_{1}, E_{2}$ and $E_{3}$ respectively were recorded fo reach extract. Then $E_{\text {corr. }}$ at $281.5 \mathrm{~m} \mu=0.654 \times$ $\left(5 E_{2}-3 E_{1}-2 E_{3}\right)$. The u.v. readings were made on a Unicam SP. 500 spectrophotometer. The amount of lathosterol in a sterol mixture was obtained by deducting the value for 7-dehydrocholesterol obtained from the spectrum from the value for total 'fast' sterol by the Moore \& Baumann method.

Radioassay. Non-saponifiable materials, azo esters and sterols were prepared by pipetting $0.2 \mathrm{ml}$. of a $\mathrm{CHCl}_{3}$ solution of the material on to a stainless-steel planchet $(1.5 \mathrm{~cm}$. diam.), the base of which was covered with a disk of lens paper (Green's no. 105). The solvent was evaporated by irradiation from above with i.r. lamps $(250 \mathrm{w})$. The lens paper ensures a uniform distribution of material over the planchet. The material was assayed to $<5 \%$. The usual corrections for background, self-absorption and coincidence were made. The geometrical efficiency of the endwindow counter was 5\% with a background of 10-12 counts/min.; that of the proportional gas-flow counter was $50 \%$.

\section{RESULTS}

Experiments in vivo. The relative amounts of the three sterols found in the intestinal mucosa of control rats and of animals dosed with cholesterol (Expts. 1-3) and lathosterol (Expts. 4-6) are shown in Table 1. The final columns in the table give the 
Table 1. Interconversion of sterols in rat intestinal mucosa

The dose was $50 \mathrm{mg}$. of cholesterol or 27-29 mg. of lathosterol/rat. Results are expressed in $\mathrm{mg}$. of sterol from the mucosa of two rats in each group. $\Delta^{7}$, Lathosterol; $\Delta^{5: 7}, 7$-dehydrocholesterol; $\Delta^{5}$, cholesterol.

\begin{tabular}{|c|c|c|c|c|c|c|c|c|c|c|}
\hline \multirow{2}{*}{$\begin{array}{c}\text { Expt. } \\
\text { no. }\end{array}$} & \multirow[b]{2}{*}{ Sterol fed } & \multicolumn{3}{|c|}{ Controls (a) } & \multicolumn{3}{|c|}{ Dosed $(b)$} & \multicolumn{3}{|c|}{ Difference $(b-a)$} \\
\hline & & $\Delta^{7}$ & $\Delta^{5: 7}$ & $\Delta^{5}$ & $\Delta^{7}$ & $\Delta^{5: 7}$ & $\overrightarrow{\Delta^{5}}$ & $\Delta^{7}$ & $\Delta^{5: 7}$ & $\Delta^{5}$ \\
\hline $\begin{array}{l}\mathbf{1} \\
\mathbf{2} \\
\mathbf{3}\end{array}$ & $\begin{array}{c}\text { Cholesterol } \\
\text { - }\end{array}$ & $\begin{array}{l}0 \cdot 20 \\
0 \cdot 40 \\
0 \cdot 54\end{array}$ & $\begin{array}{l}0.08 \\
0.02 \\
0.04\end{array}$ & $\begin{array}{r}6 \cdot 6 \\
9 \cdot 0 \\
13 \cdot 3\end{array}$ & $\begin{array}{l}0 \cdot 17 \\
0 \cdot 28 \\
0 \cdot 23\end{array}$ & $\begin{array}{l}0.01 \\
0.02 \\
0.01\end{array}$ & $\begin{array}{l}14 \cdot 5 \\
15 \cdot 2 \\
17 \cdot 7\end{array}$ & $\begin{array}{l}-0.03 \\
-0.12 \\
-0.31\end{array}$ & $\begin{array}{c}-0.07 \\
0 \\
-0.03\end{array}$ & $\begin{array}{l}+7 \cdot 9 \\
+6 \cdot 2 \\
+4 \cdot 4\end{array}$ \\
\hline $\begin{array}{l}4 \\
5 \\
6\end{array}$ & $\begin{array}{c}\text { Lathosterol } \\
\text { - }\end{array}$ & $\begin{array}{l}0 \cdot 74 \\
0 \cdot 37 \\
0 \cdot 49\end{array}$ & $\begin{array}{l}0.05 \\
0.04 \\
0.05\end{array}$ & $\begin{array}{l}15 \cdot 4 \\
11 \cdot 3 \\
22 \cdot 3\end{array}$ & $\begin{array}{l}6 \cdot 77 \\
5 \cdot 24 \\
6 \cdot 97\end{array}$ & $\begin{array}{l}1 \cdot 40 \\
0 \cdot 43 \\
1 \cdot 15\end{array}$ & $\begin{array}{l}15 \cdot 2 \\
10 \cdot 0 \\
23 \cdot 1\end{array}$ & $\begin{array}{l}+6.03 \\
+4.87 \\
+6.48\end{array}$ & $\begin{array}{l}+1 \cdot 35 \\
+0.39 \\
+1 \cdot 10\end{array}$ & $\begin{array}{l}-0.2 \\
-1 \cdot 3 \\
+0.8\end{array}$ \\
\hline
\end{tabular}

Table 2. Conversion of $\left[4-{ }^{14} \mathrm{C}\right]$ cholesterol into [4-14 C]cholest-7-enols in the rat (Expt. no. 7)

The number of rats used was 4 .

$\begin{array}{lcc}\quad \text { Sterol fraction } & \begin{array}{c}\text { Amount } \\ \text { (mg.) }\end{array} & \begin{array}{c}\text { Specific activity } \\ \text { (counts/min./mg.) }\end{array} \\ \text { Total administered } & 40 \cdot 2 & 47104 \\ \begin{array}{l}\text { Total recovered from } \\ \text { mucosa }\end{array} & 42 \cdot 4 & 9640 \\ \text { Cholesterol } & 41 \cdot 5 & 9740 \\ \text { Total cholest-7-enols } & 0.8 & 5953\end{array}$

differences between the test and control groups. Although the cholesterol levels of the mucosa from rats absorbing this sterol have risen by 30-120\% there was an appreciable drop in the lathosterol and 7-dehydrocholesterol levels instead of an increase by enzymic conversion of the additional cholesterol.

The absorption of lathosterol, however, raised the level of this sterol in the mucosa 10- to 15-fold and at the same time brought about a 10- to 25fold increase in the 7-dehydrocholesterol content above normal. About $10-20 \%$ of the absorbed lathosterol was oxidized to 7-dehydrocholesterol. There was no significant or consistent change in the cholesterol levels, so no definite conclusion can be drawn about its possible formation in these experiments.

In order to follow the behaviour of cholesterol more carefully, a new experiment was carried out with ${ }^{14} \mathrm{C}$-labelled material. $\left[4^{-14} \mathrm{C}\right] \mathrm{Cholesterol} \mathrm{was}$ administered to one group of four rats and the various sterols in the musosa were examined as before. The results are presented in Table 2.

The 'fast-reacting' sterol fraction acquired radioactivity, indicating that some of the material fed was converted into the cholest-7-enols. The specific activity of this fraction $(0.8 \mathrm{mg}$.), however, is only two-thirds of that of the much larger cholesterol pool $(42 \mathrm{mg}$.) in the mucosa. The rate of conversion or turnover of cholesterol into the 'fast-reacting' sterols must therefore be very slow. The amount of 7-dehydrocholesterol in the rat intestine was unfortunately too small in these experiments to permit separation for accurate radioassay.

Experiments in vitro. To avoid the complication of the loss of sterols from the small intestine by the normal absorption process, a number of experiments were also carried out in vitro with everted sacs. The results for the incubation of 7-dehydrocholesterol, lathosterol and cholesterol, dispersed in the medium with bovine serum albumin, are shown in Tables 3 and 4 . During the $3 \mathrm{hr}$. incubations, $50-80 \%$ of the various sterols added were absorbed by the mucosa despite the absence of bile salts. This is perhaps seen more readily in Table 4, where the composition of the sterols in the residual medium of Expts. 9 and 10 is also given.

The additional lathosterol in Expts. 11-13 produced only a small increase in the amount of 7-dehydrocholesterol but a marked rise in cholesterol. Whether the cholesterol is synthesized in this experiment via 7-dehydrocholesterol or by another route is uncertain, but the results are consistent with the 7-dehydrocholesterol route. Indeed, Expts. 8-10 show quite clearly that 7-dehydrocholesterol is readily reduced to both isomers, cholesterol and lathosterol, in approximately equal amounts. Cholesterol supplements (Expt. 14), however, cause no detectable changes in the other sterols.

\section{DISCUSSION}

The above results confirm previous observations in this Laboratory that some of the 7-dehydrocholesterol undergoing absorption is readily reduced in the mucosa to the more saturated sterols cholesterol and lathosterol. They extend them in that both steps (I and II in Fig. 1) have now been shown to be reversible. It is proposed to refer to the enzymes concerned as the 5-ene and 7-ene reductases respectively of cholesta-5:7-dienol since the steady-state equilibrium in the unfed rat favours the more saturated sterols. The term 'cholesterol dehydrogenase', used in previous papers for the enzyme acting on the $7: 8$ double 
Table 3. Interconversion of sterols by everted intestinal sacs of the rat

Each sterol was added in a $25 \mathrm{ml}$. aqueous dispersion (approx. $1 \mathrm{mg} . / \mathrm{ml}$.) with bovine albumin. Results are expressed as mg. of sterol from the mucosa of two rats' intestines in each group: $\Delta^{7}$, Lathosterol; $\Delta^{5: 7}$, 7-dehydrocholesterol; $\Delta^{5}$, cholesterol.

\begin{tabular}{|c|c|c|c|c|c|c|c|c|c|c|}
\hline & 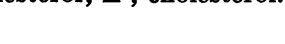 & & atrols & & & osed & & & rence $(b$ & \\
\hline $\begin{array}{l}\text { Expt. } \\
\text { no. }\end{array}$ & Sterol added & $\Delta^{7}$ & $\Delta^{5: 7}$ & $\Delta^{\mathbf{5}}$ & $\Delta^{7}$ & $\Delta^{5: 7}$ & $\Delta^{\mathbf{5}}$ & $\Delta^{7}$ & $\Delta^{5: 7}$ & $\Delta^{5}$ \\
\hline $\begin{array}{r}8 \\
9 \\
10\end{array}$ & $\begin{array}{c}\text { 7-Dehydrocholesterol } \\
-\end{array}$ & $\begin{array}{l}0 \cdot 12 \\
0 \cdot 22 \\
0 \cdot 15\end{array}$ & $\begin{array}{l}0.04 \\
0.05 \\
0.08\end{array}$ & $\begin{array}{l}3 \cdot 17 \\
2 \cdot 55 \\
4 \cdot 34\end{array}$ & $\begin{array}{l}4 \cdot 68 \\
6 \cdot 82 \\
6 \cdot 05\end{array}$ & $\begin{array}{l}5 \cdot 31 \\
4 \cdot 36 \\
6 \cdot 50\end{array}$ & $\begin{array}{l}6 \cdot 35 \\
9 \cdot 03 \\
8 \cdot 78\end{array}$ & $\begin{array}{l}+4 \cdot 56 \\
+6 \cdot 60 \\
+5 \cdot 90\end{array}$ & $\begin{array}{l}+5 \cdot 27 \\
+4 \cdot 31 \\
+6 \cdot 42\end{array}$ & $\begin{array}{l}+3 \cdot 18 \\
+6 \cdot 48 \\
+4 \cdot 44\end{array}$ \\
\hline $\begin{array}{l}11 \\
12 \\
13\end{array}$ & $\begin{array}{r}\text { Lathosterol } \\
\text { - }\end{array}$ & $\begin{array}{l}0 \cdot 08 \\
0 \cdot 09 \\
0 \cdot 26\end{array}$ & $\begin{array}{l}0.07 \\
0 \cdot 06 \\
0 \cdot 12\end{array}$ & $\begin{array}{l}6 \cdot 00 \\
6 \cdot 15 \\
5 \cdot 28\end{array}$ & $\begin{array}{l}15 \cdot 70 \\
15 \cdot 70 \\
19 \cdot 19\end{array}$ & $\begin{array}{l}0 \cdot 08 \\
0 \cdot 07 \\
0 \cdot 17\end{array}$ & $\begin{array}{r}10 \cdot 67 \\
11 \cdot 00 \\
7 \cdot 75\end{array}$ & $\begin{array}{l}+15 \cdot 6 \\
+15 \cdot 6 \\
+18 \cdot 9\end{array}$ & $\begin{array}{l}+0.01 \\
+0.01 \\
+0.05\end{array}$ & $\begin{array}{l}+4 \cdot 67 \\
+4 \cdot 85 \\
+2 \cdot 47\end{array}$ \\
\hline 14 & $\begin{array}{c}{[4.14 \mathrm{C}] \text { Cholesterol }} \\
(9.8 \mathrm{mg} ., 12.9 \mu \mathrm{C})\end{array}$ & $0 \cdot 27$ & 0.09 & $12 \cdot 30$ & $0 \cdot 26$ & 0.09 & $\begin{array}{l}20 \cdot 15 \\
(9 \cdot 2 \mu \mathrm{c})\end{array}$ & -0.003 & +0.003 & $+7 \cdot 85$ \\
\hline
\end{tabular}

Table 4. Uptake of sterols from aqueous medium by everted intestinal sacs

The initial medium was Krebs \& Henseleit (1932) bicarbonate buffer (pH 7.4) containing $1 \mathrm{mg}$. of sterol/ml. dispersed with bovine albumin. Incubation period, $3 \mathrm{hr}$.

\begin{tabular}{|c|c|c|c|c|c|c|c|c|}
\hline $\begin{array}{l}\text { Expt. } \\
\text { no. }\end{array}$ & $\begin{array}{l}\text { Sterol added } \\
\text { to medium }\end{array}$ & $\begin{array}{c}\text { Quantity } \\
\text { (mg.) }\end{array}$ & Group & $\begin{array}{c}\text { Cholesterol } \\
\text { (mg.) }\end{array}$ & $\begin{array}{l}\text { 7-Dehydro- } \\
\text { cholesterol } \\
\text { (mg.) }\end{array}$ & $\begin{array}{l}\text { Lathosterol } \\
\text { (mg.) }\end{array}$ & $\begin{array}{l}\text { Total } \\
\text { sterols } \\
\text { (mg.) }\end{array}$ & $\begin{array}{c}\text { Uptake } \\
(\%)\end{array}$ \\
\hline 9 & 7-Dehydrocholesterol & $\begin{array}{c}0 \\
26 \cdot 4\end{array}$ & $\begin{array}{l}\text { Control } \\
\left\{\begin{array}{c}\text { Test } \\
\text { Final test- } \\
\text { medium }\end{array}\right.\end{array}$ & $\begin{array}{l}2 \cdot 55 \\
9 \cdot 03 \\
4 \cdot 71\end{array}$ & $\begin{array}{l}0 \cdot 05 \\
4 \cdot 36 \\
1 \cdot 36\end{array}$ & $\begin{array}{l}0 \cdot 22 \\
6 \cdot 82 \\
0 \cdot 59\end{array}$ & $\begin{array}{r}2 \cdot 82 \\
20 \cdot 21 \\
6 \cdot 66\end{array}$ & $\overline{66}$ \\
\hline 10 & 7-Dehydrocholesterol & $\begin{array}{c}0 \\
23 \cdot 9\end{array}$ & $\begin{array}{l}\text { Control } \\
\left\{\begin{array}{c}\text { Test } \\
\text { Final test- } \\
\text { medium }\end{array}\right.\end{array}$ & $\begin{array}{l}4 \cdot 34 \\
8 \cdot 78 \\
1 \cdot 40\end{array}$ & $\begin{array}{l}0 \cdot 08 \\
6 \cdot 50 \\
0 \cdot 20\end{array}$ & $\begin{array}{l}0 \cdot 15 \\
6 \cdot 05 \\
0 \cdot 30\end{array}$ & $\begin{array}{r}4 \cdot 57 \\
21 \cdot 33 \\
1 \cdot 90\end{array}$ & $\overline{70}$ \\
\hline
\end{tabular}

bond (Glover et al. 1952), is now regarded as unsuitable since it has also been used for the enzyme catalysing the oxidation of the $3 \beta$-hydroxy group.

5-Ene reductase. With regard to the 5-ene reductase, experiments both in vivo and in vitro show clearly that the reduction of a single dose of 7-dehydrocholesterol to lathosterol can take place rapidly. ('Single dose' is emphasized here because unpublished observations indicate that as the absorption of 7-dehydrocholesterol is prolonged over $24 \mathrm{hr}$. the capacity of the mucosal system to reduce it to lathosterol becomes much smaller.) The results for the oxidation of lathosterol, however, are slightly different in vitro compared with in vivo. Whereas the ratio of lathosterol to 7dehydrocholesterol in the mucosa of the unfed rat lies in the range 10-12 (see Table 1), in animals dosed with lathosterol this was lowered slightly to 5-12 in spite of a more than tenfold increase in the absolute amount of lathosterol present in the tissue. Thus, in vivo, the oxidation of lathosterol to 7dehydrocholesterol takes place readily. However, in vitro, 3-6 hr. after incubation of the control everted sacs, the above ratio declined to 1-4, mainly owing to a lower lathosterol content (Table 3). In the presence of added lathosterol, the ratio rises to $100-200$ with only a slight increase in the 7-dehydrocholesterol. The cholesterol level on the other hand rises markedly. This suggests that any 7-dehydrocholesterol formed is immediately reduced in the 7-position to cholesterol. The low concentration of 7-dehydrocholesterol may reflect a less efficient state of aeration of the mucosa in the isolated sac compared with that in the normal intestine. The requirement for oxygen in the transformation of lathosterol into cholesterol has been observed by Frantz et al. (1959).

7-Ene reductase. The above results from experiments on the administration of cholesterol to rats and work with 7-dehydrocholesterol (Glover \& Stainer, 1959) suggest that, if a 7-ene reductase is active, the amount of 7-dehydrocholesterol formed from cholesterol and vice versa was either too small to be detected or else it merely replaced endogenous material swept into the lymph by the normal exchange process that occurs during absorption. The fact that the formation of cholesterol from 7-dehydrocholesterol is readily detected in vitro implies that the latter explanation is probably correct. At least, the reduction of 7dehydrocholesterol to cholesterol can take place, although apparently less readily than to lathosterol in vivo.

When $\left[4^{-14} \mathrm{C}\right]$ cholesterol was administered to rats, it was possible to demonstrate the formation of the corresponding ${ }^{4-14} \mathrm{C}$-labelled 'fast-reacting' 
sterols but their combined specific activity is twothirds of that of the cholesterol, which is present in 52 times their total amounts (Table 2). The oxidtion of about $0.5 \mathrm{mg}$. of cholesterol back to the 'fast-reacting' sterols would account for the above result. Thus the reaction takes place only slowly. A possible explanation is that only a portion of the cholesterol is exposed to the enzyme. Previous work, however, shows that the exchange or turnover of the various sterols with one another in the cell is so rapid that this should not really be considered a serious limiting factor in cholesterol oxidation. Similarly, in vitro, cholesterol is not readily converted into the 'fast-reacting' sterols.

The evidence as a whole suggests that conditions in the cell favour the formation of cholesterol from lathosterol via 7-dehydrocholesterol rather than the reverse reactions, so the 'fast-reacting' sterols are precursors of cholesterol rather than metabolites. This may not, however, be the only biosynthetic route for the formation of cholesterol, for desmosterol (cholesta-5:25-dienol) can also be converted into cholesterol (Stokes, Hickey \& Fish, 1958).

The above sequence, however, is in keeping with the work of Brooks \& Baumann (1957) with [2-14 C]acetate and our own recent work with $\left[2-{ }^{14} \mathrm{C}\right]$ mevalonate, a preliminary account of which has been published (Mercer \& Glover, 1959).

Intestinal mucosa homogenates prepared by the Bucher procedure (Bucher \& McGarrahan, 1956) were tried several times for their capacity to interconvert the various sterols, but their activity was invariably low although they can synthesize sterols from $\left[{ }^{14} \mathrm{C}\right]$ acetate or $\left[{ }^{14} \mathrm{C}\right]$ mevalonate. Frantz et al. (1959) also appeared to have difficulty with liver homogenates in studying the same reaction.

All the sterols suspended in the bovine serum albumin were well absorbed by the intestinal sacs without the addition of bile salts. Thus the main function of the latter in sterol absorption is probably due to their dispersing action.

That true absorption across the cell membrane is occurring and not simple adsorption on it is indicated by the fact that in Expts. 8-10 the absorbed 7-dehydrocholesterol is reduced to lathosterol. This reaction does not occur under the above conditions when the cell membranes are broken. In fact, the results for the sterol composition of the residual medium, after incubation, indicate that some cholesterol and lathosterol secretion has taken place concomitantly with 7-dehydrocholesterol absorption.

\section{SUMMARY}

1. 7-Dehydrocholesterol and lathosterol are readily interconverted in the intestine of the rat in vivo and in vitro. The equilibrium of the enzyme system favours lathosterol. The relative ease with which this reaction takes place indicates that the enzyme involved may be a reductase, which has been tentatively called ' 7 -dehydrocholesterol 5-ene reductase'.

2. A little 7-dehydrocholesterol is simultaneously reduced to cholesterol in the same tissue but at a much lower rate than the above interchanges. The back reaction, cholesterol to 7-dehydrocholesterol, proceeds even more slowly. The enzyme system responsible for this step has been tentatively called '7-dehydrocholesterol 7-ene reductase'.

3. The above results imply that the cholest-7enols are precursors of cholesterol rather than metabolites.

4. Each of the sterols dispersed in bovinealbumin solution was readily absorbed by everted intestinal sacs in vitro without the addition of bile salts. This shows that the sterol-absorption system is not completely dependent on bile.

\section{REFERENCES}

Brooks, G. C. J. \& Baumann, C. A. (1957). J. biol. Chem. 229, 329.

Bucher, N. L. R. \& McGarrahan, K (1956). J. biol. Chem. 222, 1 .

Cook, R. P., Kliman, A. \& Fieser, L. F. (1954). Arch. Biochem. Biophys. 52, 439.

Frantz, I. D., jun., Davidson, A. G., Dulit, E. \& Mobberley, M. L. (1959). J. biol. Chem. 234, 2290.

Glover, J., Goodwin, T. W. \& Morton, R. A. (1947). Biochem. J. 41, 97.

Glover, J. \& Green, C. (1957). Biochem. J. 67, 308.

Glover, J., Green, C. \& Stainer, D. W. (1959). Biochem. J. $72,82$.

Glover, J. \& Stainer, D. (1959). Biochem. J. 72, 79.

Glover, M., Glover, J. \& Morton, R. A. (1952). Biochem. J. $51,1$.

Idler, D. R. \& Baumann, C. A. (1952). J. biol. Chem. 195, 623.

Johnston, J. D. \& Bloch, K. (1957). J. Amer. chem. Soc. $79,1145$.

Krebs, H. A. \& Henseleit, K. (1932). Hoppe-Seyl. Z. 210, 33.

Mercer, E. I. \& Glover, J. (1959). Biochem. J. 73, 5P.

Moore, P. R. \& Baumann, C. A. (1952). J. biol. Chem. 195, 615.

Morton, R. A. \& Stubbs, A. L. (1946). Analyst, 71, 348.

Schenck, F., Buchholz, K. \& Wiese, O. (1936). Ber. dtsch. chem. Ges. 69, 2696.

Schoenheimer, R. \& Dam, H. (1933). Hoppe-Seyl. Z. 215, 59.

Schwenk, E. \& Werthessen, N. T. (1952). Arch. Biochem. Biophys. 40, 334.

Smith, A. L., Hauk, R. \& Treadwell, C. R. (1958). Amer. J. Physiol. 193, 34.

Stokes, W. W., Hickey, F. C. \& Fish, W. A. (1958). J. biol. Chem. 232, 347.

Wilson, T. H. \& Wiseman, G. (1954). J. Physiol. 123, 116.

Windaus, A. (1909). Ber. dtsch. chem. Ges. 42, 238. 